ESTUdIOS INTERNACIONALES I 58 (2007) - ISSN 07 I 6-0240 • I33-I 47 Instituto de Estudios Internacionales - Universidad de Chile

\title{
Aspectos procesales de la jurisdicción del CIADI: medidas provisionales y rechazo por manifiesta falta de fundamento
}

Procedural aspects of ICSID jurisdiction

\author{
Nelly Pazó León ${ }^{*}$ \\ Elena Yubero Gonçalves**
}

\section{Resumen}

El Centro Internacional de Arreglo de Diferencias Relativas a Inversiones (CIADI) fue creado por el Convenio sobre Arreglo de Diferencias Relativas a Inversiones entre Estados y Nacionales de Otros Estados que entró en vigencia el 16 de octubre de 1966 como un sistema multilateral capaz de frenar el uso de la fuerza y dar una efectiva solución a las disputas entre Estados ocasionadas por los daños que un Estado receptor o un particular sufrieran en el desarrollo de sus inversiones. Chile, pese a haber sido uno de los detractores más importantes en la década de los sesenta, depositó el instrumento de ratificación del referido tratado el 24 de septiembre de 1991.

Palabras Clave: medidas provisionales, manifiesta, fundamento, CIADI.

Abogado, Pontificia Universidad Católica de Chile. (npazo@carey.cl).

Abogado, Pontificia Universidad Católica de Chile (eyubero@carey.cl).

Recibido el 20 de agosto de 2007, aceptado el 1 de octubre de 2007. 


\section{Abstract}

The Convention on Settlement of Investment Disputes between States and Nationals of Other States (ICSID) provides for the settlement of disputes between host States and foreign investors through arbitration or conciliation. The Convention and the Arbitration Rules provides for the possibility of requesting interim measures for the protection of parties`rights and conserving evidence, among others. Although rule 39 of the Arbitration Rules lists some requirements, this article will exarmine those that must be met in the request. We will also deal with the recent amendment of rule 41 (5), that looks for the protection of procedural good faith, guarantees the efficiency of the arbitral proceedings and avoids the multiplication in unnecessary cases, expenses and delays in the final award.

KEY WORDS: interim measures, manifestly merit, ICSID 


\section{INTRODUCCIÓN}

El CIADI es un mecanismo descentralizado de solución de controversias que permite el empleo de tres tipos de procedimientos arbitrales: a) el procedimiento CIADI, amparado en su institucionalidad, en el hecho de que existe jurisprudencia disponible y en su sistema de ejecución y cumplimiento de laudos; b) el procedimiento UNCITRAL opción que va aparejada a la elección del administrador del procedimiento y que carece de un órgano que centralice la jurisprudencia, pero en el que se acepta la apelación de los laudos según la legislación de la sede escogida, y c) la designación de un tribunal ad hoc.

Los tribunales del CIADI conocen de acciones por daños y perjuicios y de acciones de expropiación directa e indirecta (o normativa) contra el Estado. En consecuencia, estamos frente a un sustituto de la litigación clásica de derecho administrativo chileno: responsabilidad del Estado y expropiación. De este modo, los conflictos que en estas materias se susciten entre los inversionistas extranjeros y el Estado se sitúan por encima de los tribunales locales, no solo en cuanto se puede evitar demandar ante estos, sino en el sentido de que permite revisar una resolución judicial de un juez chileno. Pero lo más importante es que nos encontramos frente a una solución arbitral de controversias sobre asuntos que se han considerado como no disponibles por las partes.

Dentro del sistema del CIADI cabe destacar el Mecanismo Complementa- rio, que permite que sean sometidas a su competencia las controversias que se susciten en casos en que el CIADI no era competente de acuerdo con las propias disposiciones del Convenio de Washington, ya sea porque el Estado receptor no era un Estado contratante del Convenio o porque tampoco lo era el Estado del nacional (inversionista). Así, el Consejo Administrativo decidió que el Mecanismo Complementario debía operar a través de cláusulas compromisorias contractuales y autorizó a su Secretaría para administrar procedimientos de conciliación y arbitraje en materia de inversiones, para intervenir en procedimientos de conciliación y de arbitraje para el arreglo de diferencias que no surjan directamente de una inversión y en que al menos una de las partes sea un Estado contratante o un inversionista de un Estado contratante a condición de que no se trate de una transacción comercial ordinaria, y por último, en procedimientos de acreditación de hechos. Este mecanismo no solo ha sido utilizado desde su creación sino que ha sido aceptado en tratados internacionales suscritos entre países que no eran miembros del Convenio (Canadá, actualmente en proceso de ratificación, y México, en el Tratado de Libre Comercio de América del Norte, conocido como NAFTA por su sigla en inglés).

Recientes modificaciones a las reglas de arbitraje del Centro han abordado también el desafío impuesto por la creciente carga de trabajo que debe asumir. Durante sus primeros seis años 
de existencia no hubo casos sometidos a su jurisdicción. En los primeros 26 años hubo, en promedio, un caso anual, mientras que en 2003 ingresaron 24 casos. En la actualidad ingresa un promedio de dos casos mensualmente (Lew, 2004: 269).

Una de las áreas más interesantes y que implica desafíos en el arbitraje internacional es la protección de los derechos de las partes al momento de solicitar una medida provisional. Las partes no solo esperan que sus derechos sean reconocidos al momento de dictarse el laudo, sino que exigen que sus derechos e incluso sus pretensiones sean tutelados cuando aún está pendiente la tramitación del caso, debido a que la propia existencia de una de las partes podría depender de la medida solicitada.

Este tipo de medidas ha surgido como una solución a casos urgentes en que la demora normal del pronunciamiento del laudo definitivo puede ocasionar consecuencias nefastas, pero siempre viéndose el tribunal arbitral obligado a resguardar la juridicidad del laudo y a hacer prevalecer el respeto a las garantías de un debido proceso.

Actualmente, las medidas conservativas pretenden neutralizar dos de los principales principios que se deben respetar en el arbitraje, a saber: a) la rapidez y b) la certeza jurídica (Cremades s/a), contrarrestando los efectos que un procedimiento legal puede causar a una de las partes si el proceso se prolonga durante años.

La materia es compleja no solo en la teoría sino que también en la práctica, pese a lo cual este tipo de medidas son una herramienta útil para conservar el statu quo durante la sustanciación del proceso e incluso incentivar una negociación que tienda a un avenimiento antes del inicio de las audiencias. En ciertos casos, son esenciales para la conducción y eficacia de un procedimiento arbitral en que las partes no están dispuestas a ceder en sus pretensiones o incluso para paralizar las actividades de la contraparte. Estos factores convierten las medidas provisionales en un arma de doble filo, pues pueden ser empleadas con el único fin de alargar los procedimientos y la ejecución del laudo final.

Por regla general, las disposiciones que regulan este tipo de medidas no indican los requisitos de fondo y de forma que deberán cumplirse para que el tribunal arbitral las otorgue, como es el caso de los reglamentos de la American Arbitration Association (AAA), del International Center for Dispute Resolutions (ICDR) y del International Chamber of Commerce (ICC), circunstancia que, que en la práctica ha llevado a que los tribunales arbitrales no sean propensos a otorgarlas aun en casos de necesidad evidente, ya sea por una errada interpretación del concepto de «urgencia»-que se viene arrastrando desde hace años- o del concepto de «daño irreparable», en vez de entender éste último como un daño serio o sustancial, o por el simple hecho de transformar el análisis de la existencia de jurisdicción prima facie o del mérito de la solicitud en tediosos exámenes del 
fondo del caso, cayendo en una conducta que se aleja de lo que las partes quisieron al momento de pactar una cláusula arbitral, que es la eficiencia.

Excepción a lo antes señalado son el artículo 47 de la Convención y la Regla 39 del Reglamento de Arbitraje Internacional del CIADI, que han sido un mecanismo esencial no solo para la dictación de medidas provisionales en este tipo de arbitrajes sobre inversiones, sino como modelo en los arbitrajes internacionales netamente comerciales, puesto que enumeran los requisitos de fondo para otorgarlas y autorizan a las partes para excluir expresamente la facultad de solicitar medidas provisionales o limitar las facultades del propio tribunal al momento de ordenarlas ya sea restringiendo las circunstancias en que se puedan otorgar o el tipo de medidas a ordenar.

De acuerdo con esta regla 39 del Reglamento, los requisitos son los indicados en su numeral 1.

«(1) En cualquier etapa una vez incoado el procedimiento, cualquiera de las partes puede solicitar que el Tribunal recomiende la adopción de medidas provisionales para la salvaguardia de sus derechos. La solicitud deberá especificar los derechos que se salvaguardarán, las medidas cuya recomendación se pide, y las circunstancias que hacen necesario la dictación de tales medidas».

Resulta interesante que si bien detalla los requisitos de la solicitud de las partes, el tribunal pueda recomendar de oficio este tipo de medidas o bien orde- nar las que estime apropiadas, aunque las propias partes hayan solicitado otra e incluso regula el momento en que se gatilla el derecho a solicitarlas, ya que utiliza el término «incoado», que daría lugar dos interpretaciones: a) que se interprete la norma en el sentido de que no basta que se haya registrado la demanda, pues incoado significa que se haya iniciado el procedimiento o trabado la litis; o, b) que la sola solicitud de registro implica que se encuentra incoado, produciéndose un espacio en que las partes no podrían solicitarlas.

En cuanto a los derechos cuya salvaguarda se pretende, la petición generalmente incluirá la de no agravar la controversia, que el laudo sea susceptible de cumplirse y no se transforme en extemporáneo y, desde el punto de vista procesal, el resguardo de la prueba, la confidencialidad del procedimiento etc. En cuanto a la no agravación de la disputa, ver caso Amco v. Indonesia, en el que la solicitud del demandado pidiendo que el demandante cesara su conducta de publicar en la prensa reportajes fundamentando su escrito en que esa actitud podría «lead to serious exacerbation of the dispute between the parties and irreparable harm to the economy of Indonesia. El tribunal puso énfasis en que no habría agravación de la disputa ya que: "The Tribunal finds, as admitted by Respondent, that the article published in the Business Standard could not have done any actual harm to Inddonesia, nor aggravate or exacerbate the legal dispute now put before the Tribunal». 
Posteriormente el mismo tribunal señaló: «... the good and fair practical rule, according to which both Parties to a legal dispute should refrain, in their own interest, from doing anything that could aggravate or exacerbate the same, thus rendering its solution possibly more difficult». En el segundo caso, Pey v. Chile, (CIADI, 2002), el tribunal recalcó: «... En efecto, este principio fue indiscutiblemente consagrado desde hace varios decenios por la jurisprudencia internacional, y en especial desde el precedente sentado en el célebre caso Compañía de Electricidad de Sofia y de Bulgaria (medidas provisionales), Orden de 5 de diciembre de 1939 de la Corte Permanente de Justicia Internacional, serie A/B - fasc. $\mathrm{N}^{\circ} 79$, página 199 , caso en el cual la Corte indicó provisionalmente que, "en espera de su sentencia definitiva", el Estado búlgaro «should ensure that no step of any kind is taken capable of prejudicing the rights claimed by the Belgian Government or of aggravating or extending the dispute submitted to the Court» y en el caso Holiday Inn v. Morocco, se afirmó: "...international legal precedent... permit provisional measures in cases of aggravated tension, even if the conduct at issue did not affect the particular rights in dispute» (CIADI, 2002).

En cuanto al tipo de medidas cuya recomendación se puede solicitar, el Reglamento no lo menciona y la Convención se refiere a "cualquier tipo» de medidas. La jurisprudencia del CIADI nos indica que van desde la petición de obtener documentos y resguardar la prueba y las evidencias que puedan desaparecer; la petición de garantías; que se impida la existencia de un procedimiento judicial paralelo en los tribunales locales de uno de los Estados de las partes e incluso que se sancione o paralice una propaganda o publicidad considerada hostil por una de las partes y que tienda a agravar el conflicto. La naturaleza de las medidas a ser recomendadas dependerá de las circunstancias particulares del caso y de los derechos que se deban proteger. Es por ello que incluso se podrán solicitar un discovery y una medida que deba ser adoptada en un Estado que no sea parte en el procedimiento. Si bien esta última circunstancia dificulta el cumplimiento de la medida, los tribunales locales deberán considerar que si el Estado al que pertenecen es Parte en la Convención, están obligados a asegurar de buena fe que se cumpla su objetivo. Pese a la amplitud de las medidas que se pueden solicitar, la regla 39 es clara al disponer que no procederán medidas ex parte, esto es, sin previa audiencia de la otra parte, ya que ordena expresamente que se podrán otorgar solo después de dar a cada parte la oportunidad de hacer presentes sus observaciones. Con ello se cierra completamente a esa posibilidad, llevando lo contrario a un vicio de procedimiento que acarrearía la anulación del laudo.

Entendemos que el Reglamento permite a las partes, siempre que lo hayan estipulado en el convenio en que consta su consentimiento, solicitar a cualquier 
autoridad judicial o de otra naturaleza, que dicte medidas provisionales, antes o después de el procedimiento, para la preservación de sus respectivos derechos e intereses, lo que excluiría al inversionista propiamente tal, ya que de acuerdo con la definición que ella misma da de Parte no es Parte, en la Convención. Pese a que a priori esta interpretación de la norma puede parecer arbitraria, le otorga un mayor nivel de certeza al inversionista que pueda verse afectado por el poder e influencia de un determinado gobierno, ya sea ante su propio Poder Judicial o ante el poder de negociación que tenga con otro Estado.

En cuanto a la certeza que pueda otorgar el sistema respecto del cumplimiento de medidas provisionales ordenadas por un tribunal del CIADI y que tienen el carácter de recomendación, estimamos que podrán tener carácter obligatorio aun más cuando se trate de ejecución en uno de los Estados que sean parte del arbitraje. Esto porque de acuerdo con el derecho internacional los Estados son responsables de las acciones de sus respectivos Poderes Judiciales por pueden escudarse en la insuficiencia de su legislación interna.

Por lo que toca a los requisitos de fondo que un tribunal arbitral debiese exigir para otorgar medidas provisionales, a continuación revisaremos brevemente los que estimamos esenciales:

a) El examen prima facie de la existencia de jurisdicción del tribunal arbitral. De la disposición relativa al tema de la propia Convención (Schreuer,
2005. 764) se desprende la difícil tarea que enfrenta el tribunal cuando tenga que decidir sobre una medida provisional a menudo sin tener la certeza de que es competente para conocer del fondo. Pero junto con esa tarea, el tribunal y las partes se encuentran en una situación en que es urgente adoptar una medida y en que las partes no pueden esperar a que se analice a fondo el tema (Ver caso CSOB v. Slovakia ${ }^{11}$ ).

Es por ello que la Convención ha creado un sistema muy útil y al que pueden recurrir los árbitros. Se trata del Artículo 36 (3) de la Convención que dispone que será la Secretario General quien registrará la solicitud de arbitraje a menos que estime que la controversia se encuentra manifiestamente fuera de la jurisdicción del Centro. Así, a diferencia de otros procedimientos arbitrales, hay un análisis previo al que hace el mismo panel de árbitros sobre la jurisdicción. Pese a que, la decisión del Secretario General no obliga al tribunal si le otorga una base útil y contribuye a que adopte la decisión de otorgar una medida provisional. Al respecto, la parte que se vea afectada por el otorgamiento de la medida podrá luego discutir si existe o no jurisdicción.

Por ejemplo, en el caso Holiday Inn v. Marruecos, el tribunal señaló:

1 Orden Procesal No5 de 1 de marzo de 2000. $<$ (http://www.worldbank.org/icsid/cases/czechpo5.pdf $>$, consultada el 18 de febrero de 2007.

2 Web page <http://www.worldbank.org/ $\mathrm{icsid} /$ cases/Order-090605-Prov-Measures. pdf $>$, visitada el 28 de febrero de 2007. 
"The Tribunal... considers that it has jurisdiction to recommend provisional measures according to the terms of Article 47..., the Parties still having the right to express, in the rest of the procedure, any exception relating to the jurisdiction of the Tribunal on any other aspects of the dispute.»

En el caso Pey $v$. Chile, en la decisión de fecha 3 de Febrero del 2002:

Según la opinión mayoritaria y generalmente aceptada, a la Corte Internacional sólo le basta un test «prima facie», para declararse competente en la indicación de medidas provisionales «si su falta de competencia no es manifiesta y si los textos invocados por la parte demandante en los que funda la competencia de la Corte le confieren «prima facie» competencia. De cualquier manera, la cuestión se presenta de manera un tanto diferente en el marco de un arbitraje CIADI, debido a que toda la solicitud se somete, de acuerdo con el artículo 36 del Convenio, a un examen preliminar, por parte del Secretario General, de la jurisdicción del Centro (el llamado «screening»). Este último registra la solicitud "salvo que... encuentre que la diferencia se halla manifiestamente fuera de la jurisdicción del Centro.

Dentro de este requisito es importante también considerar que las medidas provisionales tienen por objeto conservar y proteger los derechos de las partes, por lo cual hay que evitar cualquier intento de prejuzgar o de anticipar el laudo sin contar con toda la información y fundamentos de derecho debe evitarse. Es por ello que la labor es compleja ya que se puede caer en uno de los dos extremos.

El tribunal arbitral del caso Pey $v$. Chile, en la misma decisión de fecha 3 de febrero del 2002, al momento de dictar la medida provisional señaló:

Por su parte, el Tribunal de Arbitraje no puede, no desea prejuzgar nada, ni siquiera, a propiamente dicho, «suponer nada por anticipado». Pero como hemos visto, el Tribunal, «si considera que las circunstancias así lo requieren, podrá recomendar la adopción de aquellas medidas provisionales que considere necesarias para salvaguardar los respectivos derechos de las partes». Durante esta etapa preliminar del arbitraje, el Tribunal no puede proceder sobre la base de "presunciones», sino más bien de hipótesis, y en especial aquella mediante la cual llegará a reconocer su competencia sobre el fondo y, en tal caso, la hipótesis en la cual los derechos que el laudo arbitral podría reconocer a una u otra de las partes involucradas en el caso estarían en riesgo de ponerse en peligro o comprometidos por la ausencia de medidas provisionales.

Posteriormente, en la misma decisión, el tribunal continúa su análisis $\mathrm{e}$ indica:

Exigir que el derecho que se pretende salvaguardar sea existente, haya sido demostrado o comprobado "al momento de la solicitud", puede ciertamente, en algunas circunstancias, no acarrear dificultad alguna. Sin embargo, en otras circunstancias, podría, ex natura rerum, obligar al Tribunal de Arbitraje a prejuzgar sobre el fondo, en un momento en donde precisamente no está en medida de juzgar, y bajo hipótesis en las que, 
por definición, la constancia o prueba de la existencia o realidad del derecho invocado no podría aportarse más que más tarde, mediante el laudo arbitral sobre el fondo del asunto.

b) un segundo requisito importante al momento de otorgar una medida provisional es la existencia del elemento urgencia y qué es lo que se debe entender por tal. En el marco del CIADI, (Schreuer, C., 2005: 751) los trabajos preparatorios de la Convención fueron poco claros al otorgaron poca claridad en este respecto. Pese a ello, se indicó que estas medidas solo se utilizarían en situaciones de absoluta necesidad y que los tribunales debían autolimitarse en su aplicación. No se intentó exigir expresamente el elemento de urgencia y de peligro inminente, pero es claro que las medidas provisionales deben otorgarse solo cuando un asunto sea tan apremiante que no se pueda esperar el laudo definitivo que se pronunciará sobre el fondo.

Pese a que el artículo 47 de la Convención no indica los requisitos sustanciales de este tipo de medidas y que ellos solo se enumeran en la Regla 39 del Reglamento de Arbitraje, la Orden Procesal dictada el 6 de septiembre de 2005, en el caso Plama $v$. Bulgaria señaló que:

Provisional measures are extraordinary measures which should not be recommended lightly. The need for provisional measures must be urgent and necessary to preserve the status quo or avoid the occurrence of irreparable harm or damage.
Con todo, el Reglamento de Arbitraje indica que deberá darse prioridad a la solicitud de una medida provisional, por lo que habrá que agilizar el procedimiento convocando a una sesión especial del tribunal o bien adoptando la medida de acuerdo con la regla 16 (2) del Reglamento. Pese a ello, y a la manifiesta intención del sistema de garantizar una reacción rápida, en la práctica el otorgamiento de medidas provisionales tarda en promedio 2 a 3 meses desde la fecha en que se solicitaron.

Cabe tener presente que hay diversas situaciones en que se dan los elementos de urgencia y necesidad. Según Christoph H. Schreuer a) Puede considerarse necesario pedir a las partes que cooperen en los procedimientos y que resguarden toda evidencia relevante; $b$ ) puede considerarse necesario adoptar medidas tempranas para asegurar el cumplimiento de un laudo; c) puede estimarse necesario frenar a las partes o evitar que busquen mecanismos por sus propios medios o a través de otros sistemas; y d) hay que impedir que se agraven las circunstancias que rodean el litigio mediante la adopción de medidas unilaterales.

c) Otro de los elementos que deben existir al momento de otorgar una medida provisional es que se produzca un daño irreparable. Tanto la Convención, como los tribunales han analizado el concepto de daño irreparable. Para que un tribunal arbitral ordene una medida provisional es 
menester que exista un daño inminente al derecho que se desea proteger y que se produzca antes de la dictación de la sentencia definitiva. La interpretación de este requisito varía de un sistema a otro. En el civil law, este requisito se conoce como periculum in mora (Schreuer, 2005: 775).

En el common law, se entenderá que esta presente este requisito cuando exista un riesgo de perjuicio irreparable, o daño. Un daño irreparable será, para una parte de la doctrina, aquel que no puede ser compensado con una indemnización de perjuicios. En este sentido Schwartz señala:

While the existence of mere financial harm is not usually the basis for exercising extraordinary power of granting interim relief, it is clear from the case law that the potential of a bankrupcy or extraordianry financial consequence which could not be repaired by damage award is a valid reason for disturbing the statu quo (Schreuer, 1989).

De este modo, en el arbitraje el peligro inminente o daño serio o sustancial será suficiente cuando la demora en la resolución de la demanda principal provocará un daño serio o sustancial a la parte que ha solicitado la medida, pero a nuestro entender no necesariamente irreparable. Berger ha basado esta postura en el artículo 26 de las Reglas de Arbitraje Uncitral las que son aplicables en procedimientos de inversión y fundamenta su postura con el mismo ejemplo que otorga este artículo con los bienes perecibles (Berger, 1993: 336).
Así, se hace necesario distinguir entre daño irreparable y daño serio o sustancial:

De acuerdo con los fallos de la Corte Internacional de Justicia, detrimento, daño o perjuicio irreparable es aquel que no puede ser compensado con una indemnización de perjuicios ${ }^{23}$ De este modo, la sola posibilidad de ocasionar un perjuicio en los derechos en litigio no es por sí suficiente para justificar que se recurra al poder excepcional de indicar medidas provisionales. Si el daño puede ser reparado fácilmente, no habrá medidas provisionales.

Este es el criterio adoptado por el CIADI, según se refleja en el caso Plama Consortium v. Bulgaria en que se señaló que un daño no es irreparable si: "If it can be compensated for by damages» (CIADI, 2006). Asimismo, el tribunal arbitral que esté conociendo de la medida, deberá tener presente que la propiedad en disputa pueda ser de aquellas que son únicas en su naturaleza o muy difíciles de reemplazar. En estos casos, una indemnización de perjuicios no será suficiente y por ende, un concepto como el de daño irreparable no serviría.

Por ello, de la aplicación de las Reglas de la UNCITRAL, del criterio que emana de ellas y de lo antes expuesto, posición que desde ya adoptamos, se desprende que la expresión daño serio o sustancial, es preferible al concepto de irreparable. Es más, pese a que este

2 Caso Pulp Mills on the River Uuruguay (Argentina v. Uruguay), CIJ orden de 13 de julio de 2006. 
concepto de «irreparable» haya sido utilizado en los Tribunales Irán-Estados Unidos, no se le debe dar una interpretación literal, ya que una de las razones para que este Tribunal empleara la expresión es que pertenece al vocabulario que emplea otro tribunal internacional, a saber, los órganos supervisores de la Convención Europea de Derechos Humanos (Caron, David D., Lee M. Caplan y Matti Pellonpää, 2006: 537). Con mayor razón en el ámbito del arbitraje sobre inversiones, no sería lógico buscar la existencia de un daño irreparable, según se ha entendido este, ya que si se espera que haya una violación tan grave de un derecho que no se pueda remediar con una indemnización de perjuicios, se perdería la razón de ser de la norma principalmente en materias económicas y no de derechos humanos.

Así lo ha entendido por ejemplo, Julian D.M. Lew, quien señala:

in this respect «irreparable» must be understood in an economic, not a literal, sense. It must take account of the fact that it may not always be possible to compensate for actual losses suffered or sullied business reputation through damages. (Lew, Mistelas Kroll, 2003: 605).

d) Finalmente, otro de los requisitos es el que se indica en el caso Maffezini v. The Kingdom of Spain, específicamente en la Orden Procesal número 2, número 21, (CIADI, 1999), en la que el tribunal señaló: "21. A determination at this time which may cast a shadow on either party's ability to present its case is not acceptable. It would be improper for the Tribunal to pre-judge the Claimant's case by recommending provisional measures of this nature».

En otro ámbito, la reciente modificación de las reglas de arbitraje internacional del CIADI en materia de inversiones respecto de la incorporación de la facultad de solicitar al tribunal arbitral el rechazo de una demanda en una etapa preliminar del procedimiento por adolecer ella de manifiesta falta de fundamento, presenta ventajas e incovenientes y deja además algunas interrogantes.

La nueva norma propende a proteger la buena fe procesal, garantizando la eficacia del procedimiento arbitral y evitando a su vez la multiplicación de procedimientos innecesarios, gastos superfluos y atrasos perjudiciales en la resolución de controversias. Por ello la modificación trata de dar más autoridad al tribunal arbitral de similar manera a un tribunal ordinario, a fin de controlar la intervención de las partes en aras de la eficacia del procedimiento, a su vez que respetando la voluntad de los litigantes como base del arbitraje. Es por ello que, a diferencia de la práctica de la Corte Internacional de Justicia, en el CIADI el análisis preliminar de la suficiencia de la fundamentación de una demanda se entrega a la voluntad de las partes.

Por otro lado la modificación enfrenta un desafío debido al aumento del número de demandas sometido a la decisión del Centro. Al respecto, en nueva regla 41 número 5 , cumple una función 
disuasiva ante eventuales demandas frívolas al imponer a los litigantes la obligación de fundar adecuadamente sus pretensiones.

Lamentablemente, la reforma tiene el inconveniente de que no importa que se presenten objeciones infundadas basadas en una supuesta falta de fundamento de la demanda. Las partes pueden entonces utilizarla entonces como mecanismo dilatorio. Otro inconveniente es que impide presentar una nueva demanda basada en los mismos hechos, cuando haya sido rechazada por manifiesta falta de fundamento. Este rechazo conduce a la dictación de un laudo no susceptible de recursos, salvo en los casos excepcionales en que procede el recurso de nulidad.

Es por ello que se hace necesario introducir un procedimiento de apelación al arbitraje del CIADI. Muchos tratados bilaterales de inversión ya lo incluyen, por lo que una reforma en este sentido contribuirá además a velar por la coherencia de es sistema de protección de las inversiones. La aplicación de la facultad consagrada en la nueva regla 41 número 5, es parte de los proyectos existentes en relación con él.

Asimismo se espera que se desarrolle un arbitraje más «judicializado» o juridictionnalisation (Legum, 2006: 283). El CIADI ha adoptado características que lo asemejen a un tribunal ordinario, por ejemplo, el procedimiento de anulación, la ejecutabilidad de los laudos en las jurisdicciones nacionales, la publicidad y la finalidad de los laudos. Este desarrollo puede verse como una manera de equilibrar las amplias facultades de los particulare de comparecer ante tribunales internacionales, de una forma única, ya que esta modificación consagra doctrinas modernas sobre la posibilidad de desviar el procedimiento arbitral, en atención a la valoración preliminar de asuntos sometidos al conocimiento del Centro, que no contemplan otros sistemas de resolución de controversias internacionales.

Finalmente, en cuanto a la ejecución y cumplimiento de los laudos en Chile, algunos podrán sostener que a los tribunales del CIADI les es aplicable el mismo razonamiento aplicado por el Tribunal Constitucional a la Corte Penal Internacional en su fallo 8 de abril de 2002, en el Rol 346, que declaró inconstitucional el Estatuto de Roma de dicha Corte, lo que se traduce en que si el Estado chileno quiere hacerse parte en el referido Tratado, debe reformar previamente la Constitución Política de la República. Nos referimos aquí al considerando 45 en virtud del cual se pueden reemplazar todas las referencias a la Corte Penal Internacional por los tribunales del CIADI, naturalmente solo desde una perspectiva netamente procesal:

45. Que como la función jurisdiccional es expresión del ejercicio de la soberanía, sólo la pueden cumplir las autoridades que la Constitución establece. El mandato de su artículo 5, inciso primero, no admite dudas sobre el particular, sea que las autoridades jurisdiccionales a que alude se encuentren dentro o fuera del Poder Judicial. De 
esta manera, a la Corte Penal Internacional el Tratado, precisamente le otorga jurisdicción para eventualmente conocer de conflictos ocurridos dentro del Territorio de la República, y que deberían ser de competencia de algún tribunal nacional. Este específico reconocimiento de potestad jurisdiccional para ser ejercida por una autoridad no establecida por nuestra Carta, entra en frontal colisión con la norma recordada, por lo que hace evidente su inconciliabilidad.

Por nuestra parte, no compartimos los razonamientos del Tribunal Constitucional, que se aferra a concepciones decimonónicas de la soberanía estatal, de la relación del Estado con la comunidad internacional y en especial del rol que corresponde al derecho internacional y a los tribunales que este establece en un mundo globalizado. Nos alarma pensar que en la medida en que la doctrina purista del Tribunal permanezca vigente, ella constituirá una amenaza para la aceptación de los fallos arbitrales de los Tribunales del CIADI (Ruiz Tagle, 2003: 186).

Pero además, consideramos que la jurisprudencia citada no solo es susceptible de crítica sino que esperamos que este artículo sirva para salvar la validez interna de los tribunales internacionales mencionados. El Tribunal Constitucional olvida que quien señala qué materias son disponibles y/o prorrogables es el legislador, y no la naturaleza, de modo que si se reconoce que el tratado tiene rango legal y que por ende es lex posterioris a las leyes chilenas vigentes sobre tal punto, lo que prima es el tratado. En otras palabras, el Tribunal
Constitucional parece haberle dado rango constitucional a las normas sobre disponibilidad de los derechos y a las normas sobre prórroga de la competencia de la ley chilena (bordali, 2002: $255)$. En definitiva, no puede aceptarse la tesis del Tribunal Constitucional, y no puede permitirse al Estado usarla como excepción al cumplimiento interno de los fallos arbitrales alegando la inconstitucionalidad del tratado del CIADI y de los Tratados Bilaterales de Inversiones (TBI) en la parte en que dan competencia a esos tribunales.

Finalmente, cabe formular una última cuestión relativa al cumplimiento de sentencias emanadas de tribunales del CIADI. La generalidad de los TBI dispone que la ejecución de estos fallos se somete a la legislación interna de los respectivos países, incluyendo los tratados existentes sobre la materia (Cremades, Cairns, 2004). En Chile, desde la dictación de la Ley 19.971 sobre Arbitraje Comercial Internacional, parece ser que ya no es necesario recurrir a los tratados internacionales celebrados por Chile en la materia. Aunque algunos puedan negar que estos casos relativos a la responsabilidad del Estado puedan calificarse de "comerciales», la verdad es que desde la perspectiva del inversionista privado sí lo son, y de hecho la existencia misma de los TBI se debe a que ponen el acento precisamente en este aspecto comercial en su sentido amplio: se trata de proteger inversiones. Además, esto concuerda con el artículo 2 letra g) de la ley mencionada, que define comercial 
en sentido amplio, incluyendo específicamente el concepto «inversión» como caso de «comercial».

Por último, el artículo $36 \mathrm{~N}^{\circ} 1$ letra b) de la Ley 19.971 sobre Arbitraje Comercial Internacional señala que: «Sólo se podrá denegar el reconocimiento o ejecución de un laudo arbitral cualquiera que sea el país en que se haya dictado...: b) Cuando el tribunal compruebe: i) que, según la ley chilena, el objeto de la controversia no es susceptible de arbitraje; o ii) que el reconocimiento del laudo sería contrario al orden público chileno».

De modo que, si se sigue la doctrina del Tribunal, de que hay materias no prorrogables por naturaleza, toda la jurisdicción del CIADI sería inconstitucional, y más aún, sus fallos no serían ejecutables en Chile. Pero, como hemos visto, el Tribunal se equivoca en este punto. Si el tratado es auto-ejecutable como, según vimos, lo es en este caso, él mismo amplía las materias prorrogables ante el derecho chileno, porque él mismo es derecho interno chileno, de igual jerarquía que el Código Civil y que el Código Orgánico de Tribunales o cualquiera otra ley pertinente. Entonces, el conflicto desaparece y la mencionada disposición de la Ley 19.971 no representa ningún peligro para la jurisdicción de los tribunales del CIADI en lo que respecta a la ejecución de sus sentencias.

\section{BIBLIOGRAFÍA}

Berger, Klaus Peter (1993), International Economic Arbitration, Deventer, Kluwer Law and Taxation Publishers.

Bordali Salamanca, Andrés (2002), Revista del Derecho (Valdivia). "Tesis sobre la constitucionalidad del Estatuto de Roma de la Corte Penal Internacional». Volumen XIII, pp. 255 a 263.

Caivano, Roque J. (1998), «Interim Measures. Interim Measures and Compulsive Measures». Revista Jurisprudencia Argentina. Volumen IV-47.

Cremades, Bernardo M. (s/a), Momento actual del arbitraje comercial internacional en América Latina. Trabajo presentado al seminario de Arbitraje organizado por AMCHAM y el Colegio de Abogados de Buenos Aires.

Cremades, Bernardo y David J.A. Cairns, (2004), "La Seguridad Jurídica de las Inversiones Extranjeras: La protección Contractual y de los Tratados", Revista de la Corte Española de Arbitraje.

Ernst, Andrea (2006), LLM en Derecho Internacional Público, Inversiones, Comercio y Arbitraje. Apuntes de clase. Universidad de Heidelberg/Universidad de Chile, 2006.

ICSID, case Pey v. Chile, decision de fecha 3 de febrero de 2002 (provisional measures).

Legum, Barton. (2006), "La Réforme du CIRDI vers une Juridictionnalisation de L’arbitrage Transnational?, in Où va le Droit de l'investissement?, Désordre Normatif et Recherché D'équilibre, Coloquio de la Universidad de Túnez, París, p. 283.

Lew, J.D.M. (2004), ICSID Arbitration: Special features and recent developments, Arbitrating Foreign Investment Disputes, Horn N. (ed.), Países Bajos, Kluwer Law International, p. 269.

Lew, Julian, Loukas Mistelis y Stefan Kröll. (2003), Comparative International Commercial Arbitration, pp. 761-804, Klumer Law International, La Haya.

Merrils, J.G. (1995), "Interim Measures of Protection in the Recent Jurisprudence of 
Pazó y Yubero • Aspectos procesales de la jurisdicción del CIADI

the International Court of Justice», International and Comparative Law Quarterly, Volumen 44, p. 105.

Ruiz Tagle, Pablo (2003), «Los derechos fundamentales en el siglo XXI y la disminución de su efecto mariposa». Revista de Derecho, Volumen XV, pp. 186 a 190.

Schreuer, Christoph H. (2001), The ICSID Convention: A Commentary On The Convention On The Settlement Of Investment Disputes Between States and Nationals of Other States, Cambridge, Cambridge University Press.
- (2005), The ICSID Convention: A Commentary, Cambridge, Cambridge University Press.

Banco Mundial, CIADI, Convención de Washington < (http://www.worldbank.org/ icsid/cases/chile-s.pdf>, visitado el 17 de febrero de 2007.

Banco Mundial, CIADI, página web link jurisprudencia, <http:/www.worldbank. org/icsid/cases/emilio_DecisiononRequestforProvisionalMeasures.pdf $>$, visitado el 16 de enero de 2007. 